\title{
Report From the Field: The RICTA Meeting Video
}

\author{
Cal Kenny \\ Knet, Keewaytinook Okimakanak < $\underline{\text { calkenny@knet.ca }>}$ \\ Brian Walmark \\ Keewaytinook Okimakanak Research Institute $<$ brianwalmark@knet.ca $>$ \\ Susan O'Donnell \\ National Research Council < Susan.ODonnell@,nrc-cnrc-gc.ca $>$
}

Video location on the web: http://streaming.knet.ca/RICTA/RICTA_300k.wmv

A short video produced about the founding meeting of RICTA has been made available for viewing online. The new Canadian research network RICTA - Research on ICT with Aboriginal Communities held its first meeting in Balmertown, Ontario, with videoconference links to 10 locations across the country.

Cal Kenny, the editor and producer of the video, is a website designer and graphic designer in Sioux Lookout, Ontario. He works for Knet, Keewaytinook Okimakanak, the Tribal Council that hosted the RICTA meeting.

The video includes footage shot on location in Balmertown and the remote fly-in community of Deer Lake First Nation, where RICTA researchers visited the community E-Centre and the TeleHealth facility. The participants interviewed for the video stress the innovative potential of ICT in Aboriginal communities - for example encouraging Aboriginal community members, particularly young people, to share their stories.

Research issues discussed include: the need for participatory methodologies that involve Aboriginal communities early in the research process, the need to ensure that research builds capacity in communities, the need to encourage community champions, and changing the conventional rules about how research is conducted. More information about RICTA can be found on the website www.ricta.ca.

Video title: RICTA - Research on ICT with Aboriginal Communities. Founding RICTA meeting and visit to Deer Lake First Nation. March 10-11, 2005

Time: 5:52

Video captured by: Cal Kenny and Daryl Ostamas

Edited by: Cal Kenny

Interviews by: Adam Fiser and Cal Kenny

Music by: Blue Mason

RICTA would like to acknowledge the support of the Social Sciences and Humanities Research Council's Strategic Research Cluster Design Grants in 2004-2005. 